\title{
Financial Performance Analysis on the Innovation of Xiaomi’s Profit Model
}

\author{
Xingyi Wang ${ }^{1, *}$ \\ ${ }^{1}$ International Education College, Tianjin University of Commerce, Tianjin 300134, China \\ *Corresponding author. Email: xingyiw9399@gmail.com
}

\begin{abstract}
At present, in the era of globalization and the rapid development of Internet services, enterprises are facing the transformation and development of the overall strategic model. For the industry that is closely related to the mobile phone which is closely related to the Internet, it is difficult to find a profit model suitable for its own development, because the definition and method of the profit model itself have a certain degree of ambiguity. Among them, when Xiaomi was established in 2010 to become one of the top 500 companies in China today, it shows that its profit model must be outstanding. Therefore, based on the innovative profit model of Xiaomi, this paper mainly studies the financial performance of the profit model, so as to conclude whether the current profit model adopted by Xiaomi is reasonable and put forward suggestions.The methods used in this article are mainly case analysis and literature research methods to evaluate the financial performance of the ecological chain in Xiaomi's innovative profit model. The results of the study found that the current innovative profit model of Xiaomi has excellent financial performance, but there will still be some problems such as low gross profit margin and lack of innovation in the ecological chain. Besides, the author also put forward suggestions that can solve Xiaomi's current problems.
\end{abstract}

\section{Keywords: Profit model, Financial performance, Xiaomi company, Ecological chain, Cost-effective}

\section{INTRODUCTION}

In the era of rapid development of the Internet, China has also become one of the main forces in the development of the Internet. The mobile phone industry is undoubtedly the cornerstone of supporting the development of the Internet, so in order to win the initiative in the mobile phone industry, it is necessary to continuously improve the innovation and development capabilities of enterprises. Specifically, it is to find a profit model suitable for the company's development so that it can innovate and seize the market [1]. In the current research on corporate profit models, some scholars will confuse the concept of profit models, and use him and business models as a kind of research. However, there are also more referential studies. For example, Gary Hamel divides the study of profit models into four major parts: renewable strategy, customer interface, strategic resources and value network [2].

This article will mainly start from the innovation points of Xiaomi's current profit model, study the financial performance brought by these innovation points, and evaluate the benefits of the profit model and put forward shortcomings and suggestions. Among them, the research of financial performance is mainly completed through structural analysis and growth analysis. The methods used are mainly literature research method and case analysis method, that is, through a large number of literature reading and special case studies, similar to reading Xiaomi's annual financial report and prospectus, so as to integrate the research to get the advantages and disadvantages of the profit model. The significance of this article's research is that in addition to providing a method for researching innovative profit models, it mainly analyzes Xiaomi's current financial situation to evaluate whether Xiaomi's profit model is reasonable.

\section{THE INNOVATION OF XIAOMI'S PROFIT MODEL}

\subsection{Price advantage}

Xiaomi has always been favored by fee-payers with its "low price and high distribution" price advantage. There are three main reasons that support Xiaomi's price advantage: Xiaomi will not invest too much in 
marketing, because Xiaomi focuses more on product development. Second, Xiao mi will rely on other products under the Xiaomi ecological chain to make profits. In addition, the hunger marketing carried out by Xiaomi has resulted in mass production and sales, so it will not cause a large amount of inventory to accumulate. This kind of mass production can ultimately increase the capital turnover rate, thereby reducing costs to a certain extent.

\subsection{Xiaomi's diversified internal and external ecological chain}

For Xiaomi's internal company, Xiaomi has formed a product design centered on mobile phones. For example, the new products launched by Xiaomi are similar to those of Xiaomi's electric cars, which are compatible with mobile phones. Therefore, Lei Jun, the founder of Xiaomi, followed the principle of "not putting all eggs in one basket" in terms of profitability.

For the external ecological chain of Xiaomi, Xiaomi will actively cooperate with its own enterprises and industries that lack resources for a long time. In this way, an industrial chain will be formed when the number of cooperative enterprises increases, thereby eliminating many intermediate costs while increasing market share and marketing capabilities. Therefore, such an ecological chain will be copied by Xiaomi into many similar industries, so that all the ecological chains will be built together to form a huge and powerful collective.

\subsection{Product mix and scale effect}

Although Xiaomi's core profit is the mobile phone business, it has also derived a series of mobile phone products based on the mobile phone business. Similar to Apple, Xiaomi will launch matching headsets, TVs, and set-top boxes. In addition, the company should now launch products such as the ecological chain, high-end household products and electric vehicles, which can be said to satisfy all aspects of life and work of buyers [3]. The most important thing is that a series of products developed by Xiaomi can be controlled with the mobile phone that Xiaomi supports, thus forming a complete set of Xiaomi ecosystem. Therefore, due to the diversity of products and the high cost-effective characteristics of the Xiaomi ecosystem, it will win continuous repeat customers, so there will be considerable economies of scale and economic benefits.

\subsection{Fan effect}

As Xiaomi has always promised that its net profit in the hardware business will only be less than $5 \%$, it has always had loyal buyers and fans in the market because of the price [4]. In addition, the main ways for Xiaomi to gain the trust of fans are the creation of 15 minutes of extremely fast customer service time to deal with problems, and humane marketing methods. Therefore, Xiaomi has won market share because of its price and good service [5]. And these markets can retain customers because of Xiaomi's continuous innovative products and high-quality services, and these customers will attract other potential customers to join. It can be seen that Xiaomi's rapid development from its establishment in 2010 to today is inseparable. The basis for such loyal customers.

\section{THE FINANCIAL STATUS OF THE PROFIT MODEL}

The new profitability of an enterprise is a means to evaluate the success of the innovative profit model adopted, if the market economy is stable. Therefore, the author will evaluate the financial performance of Xiaomi's profit model in recent years after the innovation, and will start from the horizontal comparison of similar and highly relevant companies, and the vertical comparison of the companies themselves in recent years. Specifically, the analysis will be conducted from two perspectives of structure and growth.

\subsection{Structural analysis}

After Xiaomi started to lay out the ecological chain in 2014, it has determined the industrial layout of "smartphone + LoT and consumer products + Internet services", which means that it has abandoned the model of relying solely on mobile phones and their auxiliary products. Therefore, in recent years, Xiaomi' s revenue has increased significantly in this structure. This paragraph will explore the benefits of the new profit model through the revenue and cost institutions. 


\subsubsection{Revenue structure}

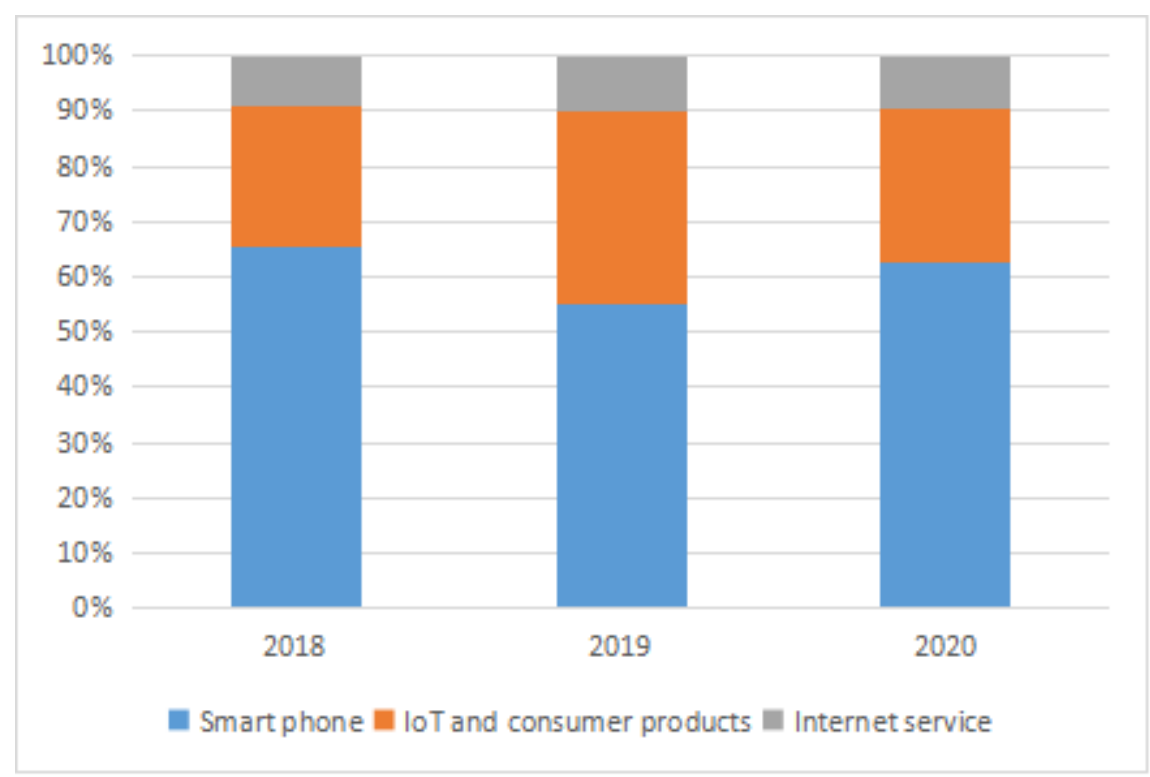

Figure 1 Xiaomi's business proportion in 2018-2020 [6]

It can be seen from figure 1 that the overall income ratio of Xiaomi's IoT to consumer goods and Internet services has increased, which echoes Xiaomi's ecological chain strategy. After 2014, Xiaomi began to develop various lifestyle products that can be used from life to work. Therefore, although mobile phone sales and revenue continue to increase, the increase in revenue from other products has also confirmed the advantages of this profit model.

Table 1. 2018-2020 Xiaomi's gross profit margin of various revenues [6]

\begin{tabular}{c|c|c|c|c|c|c}
\hline \multicolumn{2}{c|}{ Business type } & Smart phone & IoT and consumer products & Internet service & Other & Total(100\%) \\
\hline \multirow{3}{*}{2018} & Revenue & 65.1 & 25.1 & 9.1 & 0.7 & 100 \\
\cline { 2 - 7 } & Cost & 61 & 22.5 & 3.2 & 0.6 & 87.1 \\
\cline { 2 - 7 } & Gross margin & 4.1 & 2.6 & 5.9 & 0.1 & 12.9 \\
\hline \multirow{3}{*}{2019} & Revenue & 54.4 & 34.5 & 10.1 & 0.9 & 100 \\
\cline { 2 - 7 } & Cost & 50.3 & 31.3 & 3.7 & 0.8 & 86.1 \\
\cline { 2 - 7 } & Gross margin & 4.1 & 3.2 & 6.4 & 0.1 & 13.9 \\
\hline \multirow{3}{*}{2020} & Revenue & 61.9 & 27.4 & 3.7 & 0.01 & 85.2 \\
\cline { 2 - 7 } & Cost & 56.5 & 23.9 & 6 & 0 & 14.8 \\
\hline
\end{tabular}

As Xiaomi has always won the trust of consumers with low prices and high quality, it would be a good choice to study gross profit margin in income. Gross profit margin equals revenue minus expenses. It can be seen from table 1 that although the gross profit margin of smartphones is low and the proportion of revenue has dropped from $65.1 \%$ to 61.9 , there is a gradual decline overall, but its larger scale and proportion can also show that Xiaomi's current main profit Revenue is still smartphone-related business. In addition, it can be seen that the gross profit margin of Internet-related services is quite high (almost 6\% every year), so Xiaomi can make Internet services a key development object in its future development.

\subsubsection{Cost structure analysis}

Table 2. Cost input in 2018-2020 (million yuan) [6]

\begin{tabular}{l|l|l|l}
\hline Year & 2018 & 2019 & 2020 \\
\hline Sales expense & 7993.1 & $10,378.1$ & $14,539.4$ \\
\hline
\end{tabular}




\begin{tabular}{l|l|l|l}
\hline R\&D expenses & 5776.8 & 7492.6 & $9,256.1$ \\
\hline Administrative expense & 12099.1 & 10378.1 & $3,746.4$ \\
\hline
\end{tabular}

Xiaomi has always used online as the main sales channel, which means that the investment in entities is not large, so if you want to study its cost structure, people must focus on sales, $R \& D$, and administrative expenses. Specifically, the sales expenses have nearly tripled in the past three years. This is because after Xiaomi determined the ecological chain and diversified product route, Xiaomi focused on online marketing to improve competitiveness. It can be seen from table 2 that, for $\mathrm{R} \& \mathrm{D}$ expenses, there is an annual growth rate of nearly $30 \%$ (from 5.8 billion in 2018 to 9.3 billion in 2020). This is due to Xiaomi's decision to diversify its products and invest heavily in similar to electric vehicles, high-end smart furniture or In the development of high-end electronic products, this also reflects the good layout of Xiaomi's ecological chain.

\subsection{Growth analysis}

The growth analysis of profitability is a method of measuring the ability of an enterprise, and it usually compares the indicators that need to be measured with the main profit strategy adopted by the enterprise to derive the importance and advantages of the profit model. This article's analysis of Xiaomi's growth will mainly start with the growth rate of its main business income.

Table 3. Xiaomi's main business income in 2018-2020

\begin{tabular}{c|c|c|c}
\hline & 2018 & 2019 & 2020 \\
\hline Smartphone business revenue (million) & $113,800.40$ & $122,094.90$ & $152,190.90$ \\
\hline Growth (\%) & & $7.29 \%$ & $24.65 \%$ \\
\hline $\begin{array}{c}\text { Revenue from IoT and consumer goods business } \\
\text { (million) }\end{array}$ & $43,816.90$ & $62,088.00$ & $67,410.50$ \\
\hline Growth (\%) & & $41.70 \%$ & $8.57 \%$ \\
\hline Internet service business revenue (million) & $15,955.60$ & $19,841.60$ & $23,755.30$ \\
\hline Growth (\%) & & $24.36 \%$ & $19.72 \%$ \\
\hline Main business income (million) & $174,915.40$ & $205,838.70$ & $245,865.60$ \\
\hline Main business input growth rate & & $17.68 \%$ & $19.45 \%$ \\
\hline
\end{tabular}

From table 3 , it can be seen that Xiaomi's smartphones have been growing from 2018 to 2020, except that in 2019, the growth rate of IoT and consumer goods business revenue reached $41.7 \%$, which led to a reduction in the growth capacity of mobile phones to $7 \%$. . This reflects the increase in revenue of Xiaomi's mobile phone fans in the past three years, and the characteristics of Xiaomi's combined online and offline marketing model. The revenue of IoT and consumer goods business has increased sharply by $41 \%$ in 2019. This also reflects Xiaomi's increased emphasis on the layout of the ecological chain. Finally, for Internet services, although the growth rate in the past two years is low and less than $20 \%$, Xiaomi still has an overall increase in this aspect. In summary, the growth rate of Xiaomi in the three main areas of its business is relatively stable and gradually increasing, which indirectly shows that the profit model of Xiaomi mentioned above is feasible.

\section{SHORTCOMINGS AND IMPROVEMENT METHODS}

\subsection{Insufficiency}

At present, there are two main problems caused by Xiaomi's high cost performance, namely, the lack of innovative motivation for profitability and the low gross profit margin caused by low pricing.

\subsubsection{Insufficient innovation motivation for profit points}

Based on the above research on the profitability of Xiaomi's main business income and costs, it can be concluded that Xiaomi's revenue generation from smart phones is gradually weakening. Above all, compared with its peers, the quality of Xiaomi's low-priced mobile phones is not high Moreover, the most important thing is the lack of innovation in Xiaomi smartphones. The current domestic mobile phones, including Huawei, Xiaomi and OPPO, will have the problem of insufficient innovation and lack of core R\&D technology. Therefore, Xiaomi will mainly use low prices to obtain the market, and then use these markets to sell other products of the ecological chain, and the final profit 
return will be delayed. Such a profit strategy will undoubtedly affect the process of innovation and research and development.

\subsubsection{Too low pricing leads to low gross profit margin}

It can be seen from the gross profit margin of smartphones that Xiaomi's mobile phone profit margin will not exceed $5 \%$. However, although such a low price can attract more users, the overall quantity multiplied by the total quantity is not objective, which means that Xiaomi's current market share is very low compared to its peers. Since the mobile phone industry has had a relatively mature market since 2010 , and industry giants such as Apple, Huawei and Samsung have occupied the vast majority of the mobile phone market, Xiaomi must not only focus on the current low- and mid-range market of. If it continues to rely on the current market, Xiaomi will face the risk of a huge drop in revenue from the core business of smartphones.

\subsection{Solutions}

\subsubsection{Increasing $R \& D$ investment and improve product quality}

At present, Xiaomi has made some achievements in the ecological chain and achieved a certain degree of innovation, but the quality of products and market preference should be improved [7]. In the current mobile phone and electronic product market, consumers are not only looking at the price, but also the appearance and the experience of using them after getting them. Although Xiaomi's current market share in China has reached the fourth place, according to general feedback, it can be concluded that its quality ratio cannot be equal to the top three. Therefore, if Xiaomi wants long-term development, it must increase its investment in scientific research and improve the quality of its products to win a more loyal consumer market.

\subsubsection{Expanding market share and increase mid- to high-end customer base}

At present, the company mainly has a place in China, but in terms of China's current international development speed, Xiaomi should take a long-term view to go international and increase its mid-to-high-end customer base. Based on the above analysis, it can be concluded that Xiaomi's current smart phones, IoT, consumer goods and Internet service businesses are all developing steadily, and are mainly oriented to middle and low-end users. Therefore, under the stable domestic market environment and China's current better globalized economy market conditions, Xiaomi should try its best to enlarge its own advantages and increase mid-to-high-end consumption, so as to better meet the wave of the global economy.

\section{CONCLUSION}

In conclusion, this paper found that Xiaomi's innovative profit model has price advantages, Xiaomi's diversified internal and external ecological chains, product mix and scale effect, and fan effect. First of all, the innovation of Xiaomi's profit model has brought competitiveness to the enterprise. Due to Xiaomi's continuous innovation and development, Xiaomi has made continuous financial progress in "smart phones + LoT and consumer products + Internet services", which affirms the company's efforts in the ecological chain and fan effect. Specifically, for the ecological chain, Xiaomi's move to use smartphones as the core to develop products beyond life and work is correct. In this way, Xiaomi will be able to continuously improve its own product production chain, thereby occupying more to enhance competitiveness and seize more market share

However, it is not difficult to find that this profit model still has certain risks. Specifically, for the ecological chain of Xiaomi's internal products, due to continuous innovation and research and development, the product quality may not meet the requirements of the market or not meet the needs of the market, leading to the situation of excess product and inventory accumulation. Subsequently, the profit model will affect the company's cash flow and liquidity to a certain extent, resulting in a decrease in revenue. For Xiaomi's external ecological chain, however, if Xiaomi relies too much on and cooperates with other companies too much, it is likely to be affected by other companies. For example, if there is a problem with the company that Xiaomi cooperates with, then some of the products of Xiaomi will be affected.

\section{AUTHORS' CONTRIBUTIONS}

The author finished the paper through collecting data, analyzing and writing all by herself.

\section{ACKNOWLEDGMENTS}

First of all, I want to thank my teacher Chen Xinxu. The methods and ideas of financial performance analysis used in this article are all taught to me by $\mathrm{Mr}$. Chen. In the process of writing this article, Mr. Chen has been patiently and meticulously teaching my ideas and writing techniques, which has given me a lot of help. Secondly, I want to thank my parents and friends. When I encountered difficulties and troubles, they were the ones who solved the puzzles and brought great concern to me, so that I have sufficient motivation to go forward without fear of difficulties! 


\section{REFERENCES}

[1] Bogliacino, F., \& Pianta, M. (2012). Profits, r\&d, and innovation - a model and a test. Industrial and Corporate Change, 22(3), 649-678. https://doi.org/10.1093/icc/dts028

[2] Teece, D. J. (2010). Business Models, Business Strategy and Innovation. Long Range Planning, 43(2-3), 172-194. https://doi.org/10.1016/j.1rp.2009.07.003

[3] Casadesus-Masanell, R., \& Zhu, F. (2012). Business model innovation and competitive imitation: The case of sponsor-based business models. Strategic Management Journal, 34(4), 464-482. https://doi.org/10.1002/smj.2022

[4] Lin, G., Wei, W., \& Zhu, W. (2015). The principle of profit models. https://doi.org/10.1007/978-3-662-44714-7

[5] Shih, C.-C., Lin, T. M. Y., \& Luarn, P. (2014). Fan-centric social media: The Xiaomi phenomenon in China. Business Horizons, 57(3), 349-358. https://doi.org/10.1016/j.bushor.2013.12.006

[6] Xiaomi Corporation. (2020). Annual reports and accounts. Reports and presentation. https://company.mi.com/zh-cn/ir/financialInfo/

[7] Li, M., Jia, S., \& Du, W. (D. (2019). Fans as a source of extended innovation capabilities: A case study of Xiaomi Technology. International Journal of Information Management, 44, 204-208. https://doi.org/10.1016/j.ijinfomgt.2018.09.007 